\title{
Climate Change Impacts on Energy Demand of Madrid Buildings
}

\author{
Roberto San José, Juan L. Pérez, Libia Pérez, and Rosa Maria Gonzalez Barras
}

\begin{abstract}
The future impacts of climate change on heating and cooling energy demand were investigate by building energy demand simulations by EnergyPlus model and hourly climate data for two IPCC scenarios: RCP 4.5 (stabilization emission scenario) and RCP 8.5 (little effort to reduce emissions). The climate scenarios have been downscaled from $1^{\circ}$ to 50 meters of spatial resolution over city of Madrid. A Madrid typical $1 \mathrm{~km}$ by $1 \mathrm{~km}$ area of buildings is simulated using detailed meteorological information for each building produced by a dynamical downscaling process taking into account the 3D shape of the buildings, for years 2011 and 2100 . Three types of buildings were identified: offices, hotels and apartments. The three prototypes are based on ASHRAE 90.1 Prototype Building Modeling Specifications but major characteristics have been adapted for each specific simulated building. We analyze the changes (\%) in energy demand for the heating (gas) and electricity (HVAC system) for year 2100 versus 2011. The results show an increase in cooling demand around $10.5 \%$ by 2100 with RCP 8.5. The annual heating gas demand for office buildings will increase by $64.4 \%$ while the cooling energy demand will fall by $7.8 \%$ with the RCP 4.5 because future will be cooler that the present. The results show that climate change will have a large effect in the building energy demand and the used methodology can be used to design strategies to reduce the effects of climate change.
\end{abstract}

Index Terms-Climate, downscaling, building energy, scenarios.

\section{INTRODUCTION}

Microclimatic conditions on urban areas regulate the building energy demand. The energy demand for space heating and cooling is sensitive to climate variables, e.g. air temperature radiation and wind seep and so on. Space heating and cooling and the associated energy demand is affected by climate change [1]. Changes on micro climate of the cities may change future energy consumptions patterns of the cities. Building energy consumption is vulnerable to climate change due to the direct relationship between outside climate and space cooling/heating.

The energy is used for heating and cooling the buildings. It was found that around $37 \%$ of total energy was consumed in buildings in the developed countries [2]. The rates of building energy consumption in developing countries are also expected to increase as the cities keep improving their standard of living and quality of life [3]. Heating, ventilation

Manusript received October 5, 2016; revised May 27, 2017.

R. S. Jose, J. L. Perez, and L. Perez are with Environmental Software and Modelling Group, Computer Science School, Technical University of Madrid (UPM), Madrid, Spain (e-mail: roberto@fi.upm.es, jlperez@fi.upm.es).

R. M. Gonzalez is with Department of Physics and Meteorology, Faculty of Physics, Complutense University of Madrid (UCM), Ciudad Universitaria, 28040 Madrid, Spain (e-mail: rgbarras@gmail.com). and air conditioning (HVAC) related energy consumption has been rising in recent years throughout Europe, in particular in Southern Europe. The buildings designed according to the climatic condition of recent years may become increasingly costly to operate and maintain in the present and future [4].

Under the conditions of changing climate, especially in summer, the buildings will consume more energy but with poorer indoor air quality and lower thermal comfort. Increase in temperature and extreme weather events, temperature swings, changes in relative humidity and solar radiation should be taken into account to ensure that current and future buildings are able to adapt to these changes [5]. The impact of climate change on heating and cooling energy use in different locations will vary because of their different climates, [6]. A detailed analysis of heating and cooling energy use in the future is needed to better understand the impact of climate change on building energy consumption

Energy demand sensitivities to climate change should be performed at urban scale because global or regional climate is not enough to have geographically distinct impacts [7]. In previous studies for the USA [8] and [9], the UK [10] and, Greece [11], climate change was found to have significant implications for energy consumption in buildings. These studies are regional based and only focus on a few types of buildings, thus could not predict the general. Studies of impacts on future energy demands have high uncertainty arising from uncertainties in methods of projecting future climate conditions [12].

Previous studies are using future hourly weather data generated from projections of future climates which are provided by the various global circulation models (GCM) with very coarse resolution, about $1^{\circ}$. The atmospheric flow and microclimate on urban areas are influenced by the urban characteristics [13]. Global Climate Models (GCMs) have a coarse resolution, so we need to use higher resolution numerical modelling to get precise data about the urban micro climate [14].

Last developments in computer science and atmospheric science, particularly in the use of dynamical downscaling techniques provide opportunities to investigate climate effects on the building energy demand [15].

The starting point of dynamical downscaling is typically a set of coarse-resolution large-scale meteorological fields (either from a general circulation model, GCM, or from global reanalysis data) which are used to provide the initial, and lateral and surface boundary conditions to a regional climate model (RCM). Typically, the RCM simulation does not feed back into the GCM, but adds regional detail in response to finer-scale forcing (e.g., topography, land use/land cover) as it interacts with the larger-scale 
atmospheric circulation, [16]. In case or the urban areas with building blocks, this resolution is not enough and we need to make Computational Fluid Dynamics (CFD) simulations with meters of spatial resolution. The best boundary and initial conditions should be given for real simulations, [17].

We have used a computational fluid dynamics (CFD) model to take into account the effects of buildings, ventilation effects and shade given in a city. CFD simulations are computationally very demanding but it is based on physical laws and it produces a full suite of climate outputs variables. The objective is to evaluate how climate change will affect energy demand in existing buildings. This work will allow developing a better understanding of the relationship between changing climate conditions and building energy demand.

\section{Methodology}

Madrid city is chosen to analyze the climate change impacts on energy consumption for year 2100 respect to present (2011), following two possible IPCC climate scenarios [18]. The impacts were quantified by calculating the differences between energy demands for future minus present for each climate scenario. Two climate change scenarios were simulated by incorporating two Representative Concentrations Pathways (RCP): RCP 4.5 and RCP 8.5 [19].

The 8.5 pathway arises from little effort to reduce emissions and represents a failure to curb warming by 2100 . It is characterized by increasing greenhouse gas emissions over time and represents scenarios in the literature leading to high greenhouse gas concentration levels [20].

RCP 4.5 is a stabilization scenario where total radiative forcing is stabilized around 2050 by employment of a range of technologies and strategies for reducing greenhouse gas emissions. This can be considered as a weak climate change mitigation scenario [21]

As hourly weather data series are, this study made use of a dynamical downscaling process was used to generate suitable future and present hourly weather data for the simulations with very high spatial resolution, 50 meters. The description of the dynamical downscaling method was published already, for detailed information; refer to publication [22].

To obtain the hour-by-hour energy consumption during the years, data for multiple climatic variables in the form of 8760 hourly records per variable (dry bulb temperature, wet bulb temperature, global solar radiation, wind speed, wind direction, humidity, and pressure) for each year were produced.

Weather data is used not only to drive the hour-by-hour response of the building to the climate, but also to size the systems in model, thus affecting capacities, performance curves, and possibly the types of systems to use. All the effects have an impact on the predicted energy use in the model. We are following the next methodology to get the best possible urban meteorological information

We propose a climate dynamical downscaling methodology that combines state-of-the-art of different numerical models which objective is the transformation of global model outputs into high spatial resolution products. We use a model chain consists of outputs from the
Community Earth System Model (CESM) is input to the Weather Research and Forecasting Chemical model (WRF/Chem) [23] which uses a sophisticated urban canopy model (UCM) scheme to represent near-surface processes.

Outputs from the global climate model are used as boundary and initial conditions (BSC and ICs) for the regional scale run (Europe). A nesting approach is used from regional $(25 \mathrm{~km})$ to urban level $(1 \mathrm{~km}$.). The produced $3 \mathrm{D}$ fields of meteorological variables are used as BCs and ICs for the street scale runs over the selected urban areas. At this scale the Computational Fluid Dynamics (CFD) model called the MICROSYS is applied with 50 meters of resolution. The urban climate model UCM (urban canopy model) was used inside of the WRF/Chem model for investigating the impact of the climate projections on the local urban climate and air pollution for urban scale level.

The UCM is based on the Town Energy Budget approach by Masson [24]. The UCM adopts the turbulent flux resistance network approach in the canyon as described by Harman [16c], which takes into account air re-circulating and venting for turbulent heat flux calculation within the canyon. Shadowing is represented in terms of sky view factors that depict the area of each urban surface and the sky that is visible by other urban surfaces (e.g., walls and road). The $\mathrm{UCM}$ is coupled to $\mathrm{WRF} / \mathrm{Chem}$ every simulation physics time step. WRF (meteorological model) and the UCM exchange radiation, sensible heat, latent heat and momentum fluxes are coupled to the WRF planetary boundary layer turbulence closure parameterization. MICROSYS is based into the MIMO CFD model, which takes into account buildings obstacles. The model includes steady state for Reynolds-Average Navier-Stokes (RANS) with $\mathrm{k}-\varepsilon$ turbulent model runs in a steady-state mode. Surface energy fluxes have been implemented into MICROSYS code based on the procedures applied in UCM and NOAA Land-surface model.

A micro shadow model SHAMO (UPM) has been run to calculate shadow areas (including reflections in urban areas) and short wave radiation in high resolution (meters) domains

The energy simulation used a local weather files for each building both current (2011) and projected future urban climate (2100). The meteorological data are calculated as the spatial average of the 50 meters grid cells which are around of the building block. Using the dynamical downscaling results provided by the procedure described in this section, hour weather files were created for each building block.

This resolution allows that every building block has its own meteorological datasets. To obtain the hour-by-hour energy consumption during the years, data for multiple climatic variables in the form of 8760 hourly records per variable (dry bulb temperature, wet bulb temperature, global solar radiation, wind speed, wind direction, humidity, and pressure) for each year were produced. The meteorological data are calculated as the spatial average of the 50 meters grid cells which are around of the building block.

Natural gas and electricity are one of the primary heating fuels in Madrid. Whole years heating and cooling hourly demands are calculated for each of the 94 buildings found in an area of $1 \mathrm{~km}$ by $1 \mathrm{~km}$. The building and the site are both designed to be as generic as possible to facilitate high levels of comparison between the cities. All buildings have been 
simulated using three prototype buildings: office, hotel and apartment. The $61.7 \%$ of the buildings are offices, $28.7 \%$ apartments and 9,6\% hotels. The three prototypes are based on ASHRAE 90.1 Prototype Building Modeling Specifications [25] but major characteristics have been adapted for each specific simulated building because it is intended to be the most realistic possible.

Table I describes the types of buildings used with the most important building model information.

TABLE I: PRototype BUILDINGS AND SOME PARAMETERS

\begin{tabular}{|c|c|c|c|c|}
\hline Prototype & $\begin{array}{c}\text { Window } \\
\text { To Wall Ratio }\end{array}$ & $\begin{array}{c}\text { Ceiling } \\
\text { height }\end{array}$ & $\begin{array}{c}\text { Exterior } \\
\text { Walls }\end{array}$ & $\begin{array}{c}\text { Infiltration } \\
\text { (m3/min m2) }\end{array}$ \\
\hline Apartment & 0.2 & 3 & Stucco & 0.00571 \\
\hline Hotel & 0.3 & 3.5 & Cement Blocks & 0.003568 \\
\hline Office & 0.33 & 4 & Stucco & 0.00571 \\
\hline
\end{tabular}

All 94 building blocks are different because they have different building use, area and number of floors. This strategy give us a reasonable assessment of energy demand characteristics of the entire building stock in the $1 \mathrm{~km}$ by $1 \mathrm{~km}$ Madrid area selected. . It is assumed that the buildings don't change for the future simulations to isolate effects of the global climate on the energy demand of the buildings.

There are 94 buildings; each building has been simulated with meteorological data from 2011 and 2100, with the two climate scenarios, so there are a total $94 * 2 * 2=376$ simulations for the assessment. Results have been average by building type to get representative information of offices, hotels and apartments of Madrid.

Energy demand of buildings is modelled by EnergyPlus (Department of Energy of USA). It is well-known and accepted tool in community building energy analysis worldwide [26] and the model is highly validated. Taking into account the local climate of each building, EnergyPlus calculated hourly HVAC energy demand of the building to satisfy occupant thermal comfort over a period of one year. The heating and cooling thermostat is set up to $21^{\circ} \mathrm{C}$ and $24^{\circ} \mathrm{C}$.

EnergyPlus uses sophisticated calculations of heat gain and heat loss including transient heat conduction though building envelop elements. Also it realizes the transfer of heat and mass impacting the sensible and latent heat loads due to ventilation and infiltration. A comparison of current and future building energy demand, projected by the scenarios, shows remarkable changes which are showed in the next section.

\section{RESULTS}

The first step was to generate high spatial resolution climate data (50 meters) for the future (2100) and present (2011) years, based on the two IPCC RCP 4.5 and 8.5 climate scenarios over Madrid studied area using the modelling system described in the last section. Also, one simulation (NNRP) with a real-present scenario (reanalysis data) has been run for the year 2011. This simulation will be used as evaluation simulation of the modelling system.

Relative spatial differences (50m of spatial resolution) of annual mean temperature changes between (the future) 2100 and 2011 (present) for RCP 4.5 and RCP 8.5 in the Madrid area are showed in Fig. 1 and Fig. 2 respectively.

Fig. 1 shows than with the scenario 4.5 we can observe a decrease in temperature for the year 2100 up to $16 \%$ compared to 2011. In Fig. 2, the climate scenario 8.5 results in an increase of the temperature for the year 2100 up to $10.92 \%$ compared to 2011 in this area of Madrid where the energy consumption is going to be analyzed.

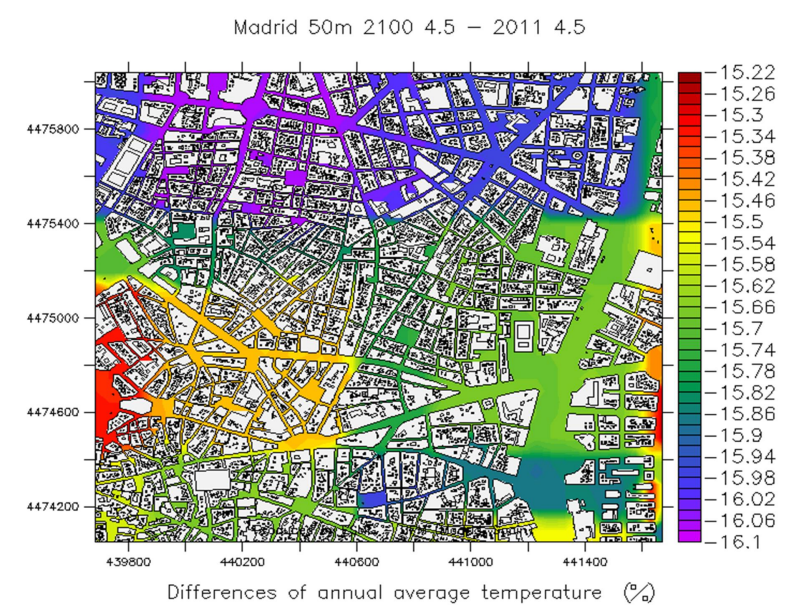

Fig. 1. Madrid differences (\%) between 2100 and 2011 spatial distribution (50 meters of resolution) of one-year average mean air temperature with RCP 4.5 .

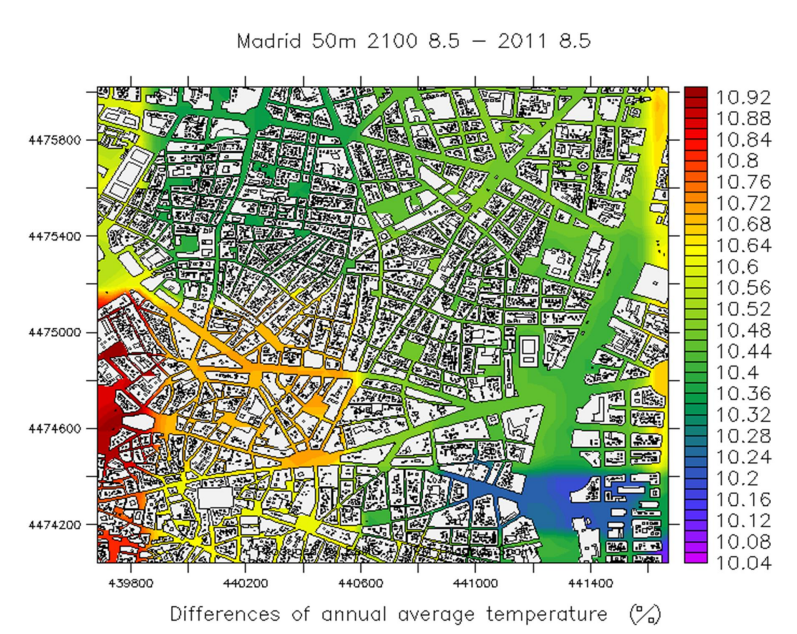

Fig. 2. Madrid differences (\%) between 2100 and 2011 spatial distribution (50 meters of resolution) of one-year average mean air temperature with RCP 8.5 .

Madrid meteorological stations were used to evaluate the accuracy of the modelling system outputs (Table II). For evaluation we have compared the hourly model outputs for present conditions (2011) following reanalysis scenario (NNRP) to hourly observations. The monitoring stations have been identified with theirs typical identifier names. "AVG Stations" means the average of the values where 
stations are located.

The following statistical metrics have been used in this study to verify the performance of the modelling system when compared with the meteorological observations of the Madrid. Bias or mean error (BIAS) is defined as the mean of the differences between the simulated outputs and observations. Root Mean Square Error (RMSE) is a frequently used measure of the difference between values predicted by a model and the values actually observed. It measures the average magnitude of the error and it is defined as the measure of the combined systematic error (bias) and random error (standard deviation).Therefore, the RMSE will only be small when both the variance and the bias of an estimator are small. Pearson correlation coefficient (R2) is defined as the measure of the linear dependence between the simulated results and the observational data, giving a value between +1 and -1 inclusive. It thus indicates the strength and direction of a linear relationship between these two variables. A value of 1 implies that a linear equation describes the relationship between models and the observations perfectly, with all data points lying on a line for which the model values increase as the data values increase. The correlation is -1 in case of a decreasing linear relationship and the values in between indicates the degree of linear relationship between the model and the observations.

The results of the comparison between the modelled data and the observed data show that the simulated values are within the ranges of measured data. The average simulated levels are within the inter-annual variability of the measured since most of the R2 values exceed the value of 0.5 , except the wind speed (WS) in some monitoring locations. The statistical evaluation shows significant evidence that high resolution downscaling procedure could achieve reasonably good performance, particularly for BIAS and R2 statistics. In case of the temperature are really good results, the prediction is within $5 \%$ error which is one of the most important input values for the energy model with very impacts on the building energy prediction.

TABLE II: MADRID RESULTS OF THE EVALUATION OF THE RESUlTS OF THE MODELLING SySTEM

\begin{tabular}{lllll}
\hline \hline & PARAMETER & NMB $(\%)$ & RMSE & R2 \\
\hline AVG STATIONS & WS (m/s) & 33,4 & 2,42 & 0,51 \\
Fuencarral & WS (m/s) & 36 & 2,24 & 0,37 \\
Moratalaz & WS (m/s) & 14,2 & 1,7 & 0,42 \\
Villaverde & WS (m/s) & 23,6 & 2 & 0,52 \\
China & WS (m/s) & 57,2 & 2,97 & 0,55 \\
Acustica & WS (m/s) & 45,8 & 2,61 & 0,41 \\
Hortaleza & $\mathrm{WS}(\mathrm{m} / \mathrm{s})$ & 36,6 & 2,44 & 0,55 \\
AVG STATIONS & $\mathrm{T}\left({ }^{\circ} \mathrm{C}\right)$ & 1,02 & 1,37 & 0,98 \\
Fuencarral & $\mathrm{T}\left({ }^{\circ} \mathrm{C}\right)$ & 3,65 & 1,58 & 0,98 \\
San Blas & $\mathrm{T}\left({ }^{\circ} \mathrm{C}\right)$ & 2,83 & 1,53 & 0,98 \\
Villaverde & $\mathrm{T}\left({ }^{\circ} \mathrm{C}\right)$ & 1,48 & 1,43 & 0,98 \\
China & $\mathrm{T}\left({ }^{\circ} \mathrm{C}\right)$ & $-3,29$ & 1,75 & 0,98 \\
Calidad aire & $\mathrm{T}\left({ }^{\circ} \mathrm{C}\right)$ & 4,77 & 2,24 & 0,96 \\
Hortaleza & $\mathrm{T}\left({ }^{\circ} \mathrm{C}\right)$ & 0,26 & 1,47 & 0,98 \\
\hline \hline
\end{tabular}

Table III shows the building type average change $(\%)$ on the annual total energy demand, annual electricity demand by the HVAC and heating gas demand of the three types of building. Gas demand shows a significant increase in the RCP 4.5 climate scenario, the increase of heating $(60 \%)$ dominates over the decrease of cooling (7\%).

Total energy demand increase between $16.54 \%$ and $22.77 \%$ from air temperature decrements. The increase in heating energy demand is much more dramatic than the decrease in cooling energy demand, when responding to the climate scenario. The total energy demand was found to increase for the buildings around $20.8 \%$ on average when the outdoor air temperature decreases $16 \%$ for year 2100 respect to 2011. Results from the simulations show that cooling energy demand, increases under RCP 8.5 project climate scenario in Madrid. It can be found that the reduction in heating demand as well as the increase in cooling demand at 2100 will make small changes in the total energy.
The RCP 8.5 may benefit from global warming in terms of the reduction in the energy demand. It is interesting to notice that increased future local temperatures translate in lower energy consumption for heating. In terms of the percentage changes in total energy demand, office and apartment buildings appears most sensitive to the RCP 4.5 climate scenario and hotels to the RCP 8.5.

Fig. 3 and Fig. 4 describe monthly average total, gas-heating and electricity-HVAC energy demand variations $(\%)$ of a mean office building. Fig. 1 corresponds with climate scenario RCP 4.5 and Fig. 2 RCP 8.5.

In Fig. 3, he monthly shows a maximum impact on energy demands in March, which increases until $250 \%$ the gas demand for heating because a strong decrement of temperature is expected to start in February (-60\%). In summer small decrements are expected thank you to reduction the cooling demand. The main reason is a high increase of the gas for because 2100 will be cooler than 2011 .

TABLE III: VARIATIONS ON ENERGY DEMAND FOR 2100 VERSUS 2011 OF 3 TYPES OF BUILDINGS

\begin{tabular}{ccccccc}
\hline \hline 2100-2011 (\%) & \multicolumn{2}{c}{ Total-Energy } & \multicolumn{2}{c}{ Electricity-HVAC } & \multicolumn{2}{c}{ Gas-Heating } \\
\hline Building/Scenario & RCP 4.5 & RCP 8.5 & RCP 4.5 & RCP 8.5 & RCP 4.5 & RCP 8.5 \\
Office & 22,77 & $-0,28$ & $-7,78$ & 10,2 & 64,43 & $-15,75$ \\
Apartment & 23,08 & $-2,24$ & $-7,04$ & 8,02 & 53,08 & $-13,08$ \\
Hotel & 16,54 & 2,25 & $-7,11$ & 13,37 & 60,89 & $-16,03$ \\
\hline \hline
\end{tabular}




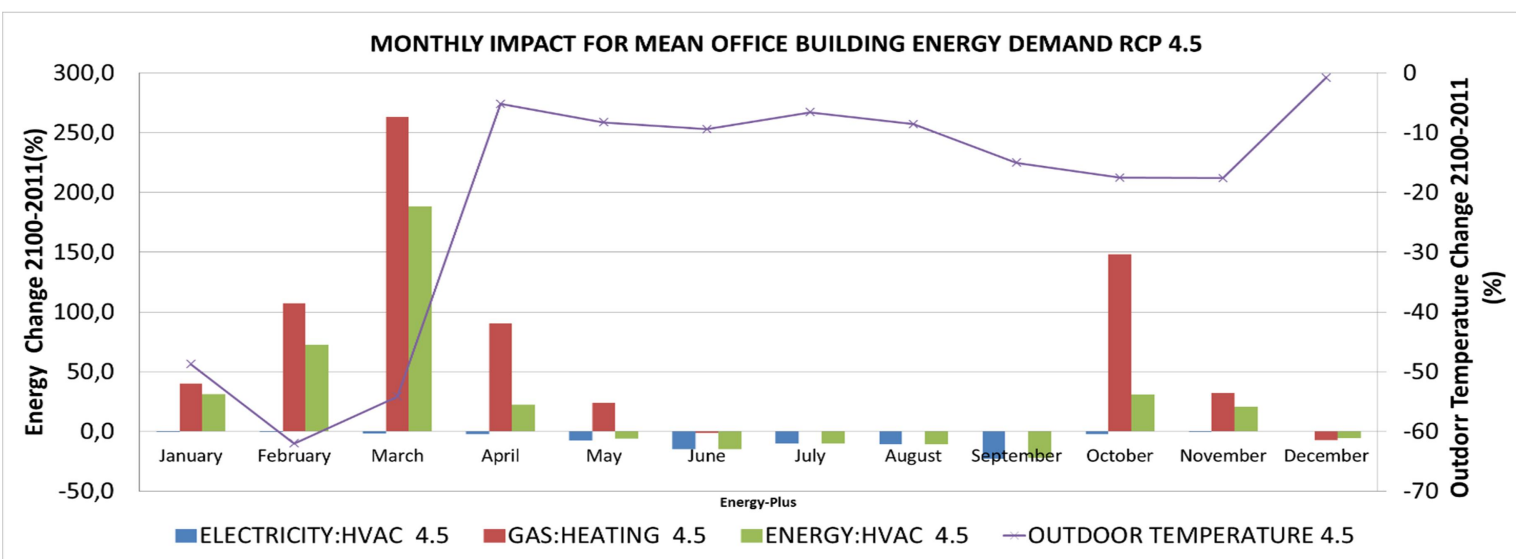

Fig. 3. Change 2100-2011 (\%) in monthly energy demand (gas and electricity) and outdoor temperature for a men office building of Madrid with RCP 4.5 climate scenario.

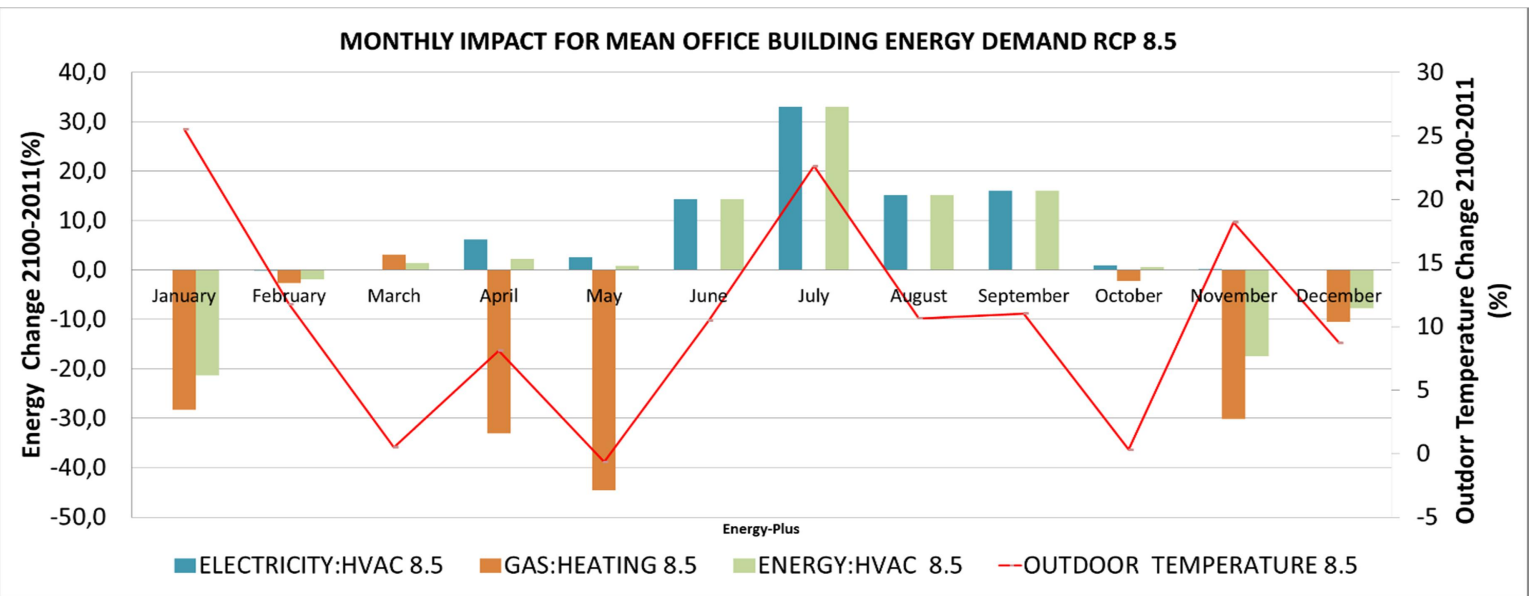

Fig. 4. Change 2100-2011 (\%) in monthly energy demand (gas and electricity) and outdoor temperature for a men office building of Madrid with RCP 8.5 climate scenario.

In Fig. 4, largest increases in building energy consumption are found in the summer where the outdoor temperature could be increase up to $25 \%$ in July. Decrease of gas demand for heating is appreciated during January, April, May, November and December. In summer, there are not changes because gas for heating are not used.

\section{CONCLUSIONS}

The objective of this research was to study the impacts of the climate change on Madrid buildings energy demand using very high spatial and temporal resolution climate data which has been dynamical downscaled from a global scale to a street level scale where a CFD model has been applied. In this study climate projections were based on two IPCC scenarios: RCP 8.5 and RCP 4.5. Heating and cooling energy consumption of 94 buildings blocks localized in area of $1 \mathrm{~km}$ by $1 \mathrm{~km}$ were simulated by using EnergyPlus, the results were averaged by three type of buildings: office, apartment and hotel.

We have showed the results for assessing energy demand responses to climate change. Results indicate that building energy demand in Madrid is very sensitive to the climate. The most serious impacts occur with the RCP 4.5 climate scenario for year 2100.

The scenario RCP 4.5 for 2100 project to increases energy demand by around $20.8 \%$, relative to the energy demand in 2011. Although the assessment is carried out for a specific building prototypes, it demonstrates that both increase in heating energy and decrease in cooling energy over the RCP 8.5 can be significant due to climate change and the opposite results could be obtained with the RCP 8.5 with increments of electricity for cooling. The RCP 8.5 will produce climate conditions that are more favourable from a building energy demand point of view because it is characterized by temperature increments, so only increments for cooling are needed. The results through changes modelled in climate indicate that climate change (RCP 8.5) will not cause an increment of the energy consumption but if it is combatted (RCP 4.5) may increase energy consumption by 2100 . In general, decreasing heating energy compensates the increased cooling energy.

The established methodology is of interest for its results and that can be applied to other buildings in other cities. These types of impacts assessments help to identify solutions that will both enhance the resilience of buildings to future climate changes. The large variations found in the relationship between climate change and building energy consumption highlight the importance of assessing climate change impacts at local scales. The results from this study could be usable by stakeholders for assisting in developing better polices on urban planning to mitigate the effects of the climate change on the energy demand.

\section{ACKNOWLEDGMENT}

The UPM authors acknowledge the computer resources 
and technical assistance provided by the Centro de Supercomputación y Visualización de Madrid (CeSViMa). The UPM authors thankfully acknowledge the computer resources, technical expertise and assistance provided by the Red Española de Supercomputación).

\section{REFERENCES}

[1] D. J. Arent et al., "Key economic sectors and services," in Climate Change 2014: Impacts, Adaptation, and Vulnerability: Part A: Global and Sectoral Aspects: Contribution of Working Group II to the Fifth Assessment Report of the Intergovernmental Panel of Climate Change, C. B. Field et al., Eds. Cambridge University Press: Cambridge, UK and New York, 2014.

[2] EIA International Energy Outlook 2014, U.S. Energy Information Administration, Washington DC, USA.

[3] N. Lior, "Energy resources and use: The present situation and possible paths to the future," Energy, vol. 33, pp. 842-857, 2008.

[4] G. H. Radhi, "Evaluating the potential impact of global warming on the UAE residential buildings - A contribution to reduce the $\mathrm{CO}_{2}$ emissions," Building and Environment, vol. 44, pp. 2451-2462, 2009.

[5] Y. H. Yau and S. Hasbi, "A review of climate change impacts on commercial buildings and their technical services in the tropics," Renew Sust Energ Rev, vol. 18, pp. 430-441, 2013.

[6] D. J. Sailor, "Relating residential and commercial sector electricity loads to climate: Evaluating state level sensitivities and vulnerabilities," Energy, vol. 26, pp. 645-657, 2001.

[7] M. Ruth and A. D. Amato, "Regional energy demand responses to climate change: Methodology and applications to the commonwealth of massachusetts," Climatic Change, vol. 70, no. 1, pp. 175-201, 2005.

[8] D. H. Rosenthal, H. K. Gruenspecht, and E. A. Moran, "Effects of global warming on energy use for space heating and cooling in the United States," Energy J., vol. 16, pp. 77-96, 1995.

[9] D. B. Belzer, J. M. Scott, and R. D. Sands, "Climate change impacts on U.S. commercial building energy consumption: An analysis using sample survey data," Energy Sources, vol. 18, pp. 177-201, 1996.

[10] S. E. C. Pretlove and T. Oreszczyn, "Climate change: Impact on the environmental design of buildings," in Proc. CIBSE A Build Serv Eng Res Technol, 1998, vol. 19, pp. 55-58.

[11] C. Cartalis, A. Synodinou, M. Proedrou, A. Tsangrassoulis, and M. Santamouris, "Modifications in energy demand in urban areas as a result of climate changes: An assessment for the southeast Mediterranean region," Energy Conversion Manage, vol. 42, pp. 1656-1674, 2001.

[12] D. H. W. Li, L. Yang, and J. C. Lam, "Impact of climate change on energy use in the built environment in different climate zones - A review," Energy, vol. 42, pp. 103-112, 2012.

[13] M. Piringer, E. Petz, I. Groehn, and G. Schauberger, "A sensitivity study of separation distances calculated with the Austrian Odour Dispersion Model (AODM)," Atmospheric Environment, vol. 41, pp. 725-1735, 2007.

[14] J. H. Christensen and O. B. Christensen, "A summary of the PRUDENCE model projections of changes in European climate by the end of this century," Climatic Change, vol. 81, pp. 7-30, 2007.

[15] C. Rosenzweig, W. Solecki, S. A. Hammer, and S. Mehrotra, "Cities lead the way in climate-change action," Nature, vol. 467, pp. 909-911, 2010.

[16] F. Giorgi and L. Mearns, "Introduction to special section: Regional climate modelling revisited," Journal of Geophysical Research, vol. 104, no. D6, pp. 6335-6352, 1999.

[17] B. Blocken, T. Stathopoulos, P. Saathoff, and X. Wang, "Numerical evaluation of pollutant dispersion in the built environment Comparisons between models and experiments," J. Wind Eng. Ind. Aerodyn., vol. 96, pp. 1817-1831, 2008.

[18] IPCC. Climate Change. The Physical Science Basis; Cambridge University Press: Cambridge, UK; New York, NY, USA, 2013

[19] D. P. Van Vuuren et al., "The representative concentration pathways: An overview," Climatic Change, vol. 109, no. 1-2, pp. 5-31, 2011.
[20] Riahi, S. Rose, P. Runci, R. Stouffer, D. van Vuuren, J. Weyant, T. Wilbanks, J. P. van Ypersele, and M. A. Zurek, "Towards new scenarios for analysis of emissions, climate change, impacts, and response strategies," Intergovernmental Panel on Climate Change, $\mathrm{p}$. 132,2008

[21] Smith, R. J. Stouffer, A. M. Thomson, J. P. Weyant1, and T. J. Wilbanks, "The next generation of scenarios for climate change research and assessment," Nature, vol. 463, pp. 747-756, 2010.

[22] R. José, J. Pérez, L. Pérez, R. González, J. Pecci, A. Garzón, and M. Palacios, "Impacts on the Urban air quality and health of global climate scenarios Using different dynamical downscaling approaches," Journal of Geoscience and Environment Protection, vol. 4, pp 168-174, 2016.

[23] G. A. Grell, S. E. Peckham, R. Schmitz, and S. A. McKeen, G. Frost, W. C. Skamarock, and B. Eder, "Fully coupled 'online' chemistry in the WRF model," Atmos. Environ., vol. 39, pp. 6957-6976, 2005.

[24] V. Masson, "A physically-based scheme for the urban energy budget in atmospheric models," Boundary Layer Meteorol, vol. 94, pp. 357-397, 2000.

[25] PNNL. Enhancements to ASHRAE Standard 90.1 Prototype Building Models. Pacific Northwest National Laboratory, Richland, Washington. (2014). [Online]. Available: https://www.energycodes.gov/development/commercial/90.1_models

[26] M. Stadler, R. Firestone, D. Curti, and C. Marnay, "On-site generation simulation with energy plus for commercial buildings," Lawrence Berkeley National Laboratory, 2006.

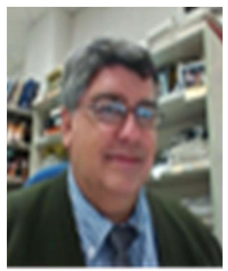

Roberto San José is a professor of the Technical University of Madrid. Director of Environmental Software and Modelling Group in the Computer Science School of UPM. He has more than 300 scientific publications in relevant Journal Citation Index Journal. He completed his PhD in 1982 related to the unstable surface turbulent boundary layer parameterisation. He has been involved in air pollution modelling mainly using three-dimensional mesoscale models, such as MM5 and CMAQ. He has been a full professor since 2001 .

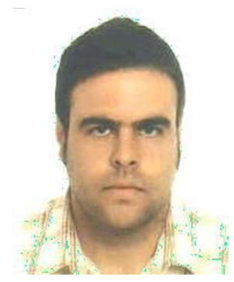

Juan Luis Pérez graduated in computer sciences at Computer Science School of the Technical University of Madrid in 2000, and in 2005, he defended a PhD thesis related to operational modelling of the MM5-CMAQ system over the internet. He has been an associate professor since 2005 and permanent professor since 2011. He is involved in some international and national research projects about atmospheric simulations and has published many papers in journals and conference proceedings.

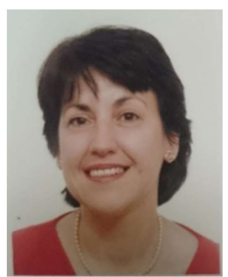

Libia Pérez is telecommunication engineering. She made the $\mathrm{Ph}$. D. in 1982 on relation to a new method for character recognition using geometric and topological structures. She has been involved in different EU projects during the last de cade joing the Environmental Software and Modelling Group in the Computer Science School of the Technical University of Madrid.

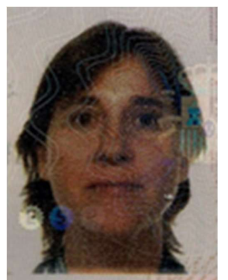

Rosa Maria Gonzalez Barras is Ph.D. in physics. Rosa M. González is an associate professor of Physics and Numerical Analysis in the Department of Geophysics and Meteorology of the Faculty of Physics of the Complutense University (UCM). She has participated several EU projects on relation to $\mathrm{Ai}$ Quality and Climate Modelling. She is an expert on MATLAB and FORTRAN programming. 